\title{
HOMOSSEXUALIDADES FEMININAS E EDUCAÇÃO: UMA REFLEXÃO SOBRE O “ARMÁRIO”
}

\author{
Andressa Costa dos Santos ${ }^{1}$, Alexandre Adalberto Pereira ${ }^{2}$ \\ ${ }^{1}$ Mestranda em Educação pelo Programa de Mestrado em Educação pela Universidade Federal do Amapá - \\ PPGED/UNIFAP. E-mail: andressacostaped@gmail.com \\ ${ }^{2}$ Doutor em Educação pelo Programa de Pós-Graduação em Educação da Universidade Federal de Uberlândia - UFU. \\ Docente do Curso de Licenciatura em Artes Visuais e do Programa de Pós-Graduação em Educação da Universidade \\ Federal do Amapá - UNIFAP.
}

\section{RESUMO}

Este artigo de revisão propõe tecer uma discussão acerca dos estudos de gênero e do percurso histórico da sexualidade como construções sociais. Apontamos para compreensão da sexualidade, permeada de valores sociais contingentes, indicamos o modo como a mulher foi colocada em uma posição de subalternidade a partir de discursos que legitimavam os corpos dos homens como sendo normais, plenos e saudáveis, em detrimento dos corpos das mulheres. Partimos da problemática que a sexualidade como construção histórica e social, pode ser apropriada pelos discursos da educação para a afirmação e/ou reconhecimento da mulher homossexual? E ao final propomos tecer diálogos sobre o dispositivo do "armário" e suas implicações na educação como forma de resistência contra a hegemonia centrada nos mecanismos de opressão.

Palavras-chave: Educação. Gênero. Sexualidade. Homossexualidades femininas.

\section{FEMALE HOMOSEXUALITY AND EDUCATION: A REFLECTION ON THE “CLOSET”}

\begin{abstract}
This review article proposes to make a discussion about gender studies and the historical course of sexuality as social constructions. We point to an understanding of sexuality, permeated by contingent social values. We indicate the way in which the woman was placed in a position of subalternity form discourses that legitimized the bodies of men as normal, full and healthy, to the detriment of women's bodies. We start from the problematic that sexuality as a historical and social construction can be appropriated by the discourses of education for the affirmation and/or recognition of the homosexual woman? And in the end we propose to weave dialogues about the device of the "closet" and its implications in education as form or resistance against the hegemony centered on the mechanism of oppression.
\end{abstract}

Keywords: Education. Gender. Sexuality. Females Homosexualities.

\section{INTRODUÇÃO}

Partindo de um conjunto de teorias que englobam sexo/gênero como construtos culturais/históricos o artigo intitulado "Homossexualidades Femininas e Educação: Um debate sobre o armário" propõe uma discussão sobre as análises e ponderações acerca do gênero e sexualidade, tendo como ponto de partida entrelaçar teorias sobre a temática das homossexualidades femininas bem como a relação do biopoder e suas implicações nas relações sociais, particularmente, no campo da educação, com o objetivo de compreender como os processos educacionais podem contribuir para a afirmação e reconhecimento da identidade da mulher homossexual historicamente estigmatizada.

Assim, se faz necessário através do percurso histórico compreender o entendimento que há sobre sexo/gênero e a crítica a partir do caráter universal e homogênio atribuída à categoria "mulher" fundamentada em torno dos debates sociais iniciados no século XVIII a respeito das essencializações, dualismos e especialmente da ideia de que gênero toma como base diferencial o dimorfismo sexual enquanto característica binária definidora de homem e de mulher - ao introduzir na sociedade 
aspectos ideológicos relacionados à continuidade e coerência entre sexo/gênero/sexualidade/desejo (LAQUEUR, 2001, p. 43-44). Sob esse prisma, 'sexo' será utilizado como termo que se refere às diferenças anatômicas básicas que distinguem homens e mulheres, mas, aos significados a elas atribuídos histórico e socialmente, temos o conceito de 'gênero' (WEEKS, 2010, p. 43).

Pretendemos desta forma, tecer uma reflexão em torno da seguinte problemática: Compreendendo a sexualidade como construção histórica e social, de que forma a educação contribui para a afirmação e/ou reconhecimento da mulher homossexual? Percebe-se que as implicações do preconceito e discriminação influenciam para se estar no "armário", enquanto categoria conceitual do campo dos estudos gays e lésbicos proposto por Eve Kosofsky Sedgwick (2007) se trata de uma prática objetiva e subjetiva de opressão das homossexualidades que são colocadas em deslocamento para um campo sigiloso - o que implica na invisibilidade das experiências de sociabilidade e de afeto de pessoas homossexuais. Para Sedgwick (2007, p. 26), o armário é "a estrutura definidora da opressão" contra gays e lésbicas. Trata-se de movimento silenciador que marca, como parte integrante, as formas como gays e lésbicas se constituem do ponto de vista de suas identidades individuais e sociais, pois ainda que o "armário" não seja uma característica exclusiva das pessoas Gays e Lésbicas é parte fundante da vida social ainda que "por mais corajosas e sinceras que sejam de hábito, por mais afortunadas pelo apoio de suas comunidades imediatas" (SEDGWICK, 2007 , p. 22) as vidas de gays e lésbicas são permanentemente marcadas pela presença formadora do armário que segundo Reynolds (1999), o armário, é refletido como uma metáfora de um dado típico contemporâneo: a de fronteiras entre o público e privado da identidade sexual. Nesse sentido o armário constrói barreiras de cunho individual e social no tocante a não visibilidade das reais demandas de mulheres homossexuais atentando para a forma como, especificamente as mulheres se relacionam com sua identidade sexual e de gênero no âmbito público/privado.

Isto posto, utiliza-se de um ensaio acadêmico de cunho crítico para instituir conhecimentos e posicionamentos acerca da temática. $\mathrm{O}$ texto está constituído e dividido em três seções. A primeira intitula-se "Os estudos de gênero e percurso histórico", a fim de abordarmos os estudos e conceito histórico em torno do debate de gênero.

A segunda "Sexualidade como construção histórica e social" apontam as questões e concepções que envolvem a sexualidade, os valores e as construções sociais que a abarcam. Por fim, a terceira seção "Afirmação e (re) conhecimento da identidade da mulher homossexual no espaço escolar" propõe tecer sobre o dispositivo do "armário" e suas implicações, bem como a contribuição da educação para estas afirmações e (re) conhecimento destas.

\section{OS ESTUDOS DE GÊNERO E PERCURSO HISTÓRICO}

É importante traçar um debate acerca do entendimento que havia em torno das diferenças entre homem e mulher na sociedade do século XVIII, que segundo Thomas Laqueur (2001), fundamentou na biologia o significado e valores sociais atribuídos a esta categoria, portanto, também ao entendimento de gênero. Além disso, é necessário abordar os avanços nas discussões sobre o conceito de gênero a partir de iniciativas feministas - ressignificando o conceito de maneira a trazer à baila na organização social a relação existente entre os sexos -, a fim de compreendermos como o significado em torno de tal conceito foi ganhando novos entendimentos, até recentemente chegarmos ao debate onde a compreensão que se tem sobre gênero como sendo performativo que para Butler (2017) é um ato intencional, produtor de significados e que está para além dos fundamentos biologizantes, binários e hierárquicos da fisiologia reprodutiva, sendo importante ser compreendido de forma não fixa, passível de transformações e mudanças.

Para Butler (2017), performatividade se trata de um exercício teórico para compreender as identidades de gênero e de sexualidade como categorias sociais e, portanto, construções históricas marcadas por atos contínuos de produção de significado. Para a autora sexo e gênero não atos pré-discursivos, produzidos na anterioridade da história, pois são claramente ficções que evocam a unicidade relacional do sexo e do gênero a partir da necessidade de manutenção da coerência interna reguladora e mantenedora das estruturas de poder que regulam as sexualidades binárias. Sendo assim, a performatividade é um exercício que mantem 
ordenada às fronteiras sociais daquilo que é considerado politicamente normal em termos de gênero e de sexualidade, tal processo opera pela estilização programada no corpo de um conjunto de atos que são continuamente repetidos na interioridade de uma disposição rigidamente ordenada, tal fenômeno se consolida no tempo para produzir a aparência de naturalidade e normalidade daquilo que de fato é contingente (BUTLER, 2017).

A sociedade do século XVIII, de acordo com Laqueur (2001), baseava-se na fisiologia reprodutiva das diferenças entre homem e mulher. Fazendo uso da cientificidade e dos fundamentos biológicos passa a considerar, no primeiro momento, o modelo de um sexo único, onde havia um sexo biológico e duas possibilidades de gênero, em que as diferenças que marcavam homem e mulher não seriam definidas pela distinção biológica de corpos divergentes entre si por conta dos aspectos anatomofisiológico, mas sim por diferenças de grau de perfeição. Dito de outro modo: homens e mulheres seriam "iguais" no aspecto dos órgãos reprodutivos, e o surgimento da diferença era marcado a partir da existência ou não de um "calor" que moldaria os corpos e internalizaria ou não os órgãos reprodutivos/genitais. Conforme Thomas Laqueur (2001) os teóricos daquela época acreditavam que:

As mulheres, em outras palavras, são homens invertidas, logo, menos perfeitas. Têm exatamente os mesmos órgãos, mas em lugares exatamente errados. [...] Da mesma forma que a humanidade é mais perfeita que o resto dos animais, dentro da humanidade o homem é mais perfeito que a mulher, e a razão dessa perfeição são seus excessos de calor, pois o calor é o instrumento básico da Natureza. (LAQUEUR, 2001, p. 43-44)

Teríamos assim, uma relação hierárquica baseada na perfeição, qual seja: a masculina pautada pelo modelo do sexo único e suas variantes de acordo com anomalias. No entanto, contrariando e refutando o modelo do sexo único; o modelo de dois sexos, segundo
Laqueur (2001) ganha força possivelmente a partir dos progressos da ciência e das mudanças políticas, econômicas e sociais do século XIX, onde as diferenças dos corpos não são mais vistas a partir de um conceito hierárquico, mas sim da incomensurabilidade biológica, isto é, diferenças radiais marcavam homens e mulheres, logo:

[...] o lugar da mulher é
determinado pelo seu
corpo, à revolução, e não
simplesmente o desejo
burguês masculino de um
'refúgio em um mundo
desalmado', gerou 'esferas
separadas'. As mulheres
eram consideradas
criaturas que, por várias
razões e sob muitos
aspectos, as mesmas que
desvalorizavam as raças
mais escuras, eram
incapazes de assumir
responsabilidade cívica
(LAQUEUR, 2001, p. 243-
244).

No modelo de dois sexos, o corpo e o sexo tornam-se fundação da sociedade, as diferenças marcadas pela biologia são atestadas pela ciência e oferecem base para vários pensadores sociais contribuírem com suas teorias fundamentadas nas diferenças inatas entre homens e mulheres e, por conseguinte as diferenciações sociais e as definições de papeis sociais entre homens e mulheres, dessa forma, as diferenças sociais são, a cada dia, reforçadas pela biologia da incomensurabilidade e pouco a pouco as distinções políticas e sociais ficam inquestionáveis (LAQUEUR, 2001, p. 241-242).

Nesse diapasão, Foucault (2009; 2006) nega a tese de que, durante a modernidade, se estabeleceu uma repressão dos discursos sexuais. Para ele, o que ocorreu foi uma mudança no eixo no qual a sexualidade estava inserida. $O$ ocidente, no momento da modernidade, situa em seu seio, uma proliferação de discursos sobre a sexualidade, objetivando estabelecer procedimentos encarregados de controlar o comportamento dos indivíduos, desse modo segundo o autor, do silenciamento, passa-se a conviver com abundantes e extensos discursos sexualizados, tendo como objetivo primaz a separação dos corpos pelas suas diferenças bio/anatômicas e ao final o correto adestramento das forças produtivas. 
Paradoxalmente, aliados a esse dispositivo científico a respeito do sexo, os sujeitos desse saber são sempre aqueles e aquelas que de alguma forma não se enquadram na normalidade (branca, masculina, heterossexual, juvenil, reprodutiva, produtiva e saudável) sendo, portanto, a saber, que os objetos desse discurso passam a ser, especificamente as mulheres, as crianças, os velhos, e todo um quinhão de diferenças incluindo desde o louco, o criminoso, passando pelos assim ditos, aborígenes, deficientes, negros, mestiços, bem como os/as homossexuais.

A ideia generalizada de uma ius naturali, um direito natural, que prevaleceu nos ideais da revolução burguesa e que considerava todos naturalmente iguais, teve que se basear justamente numa explicação biológica/naturalizante, que distinguia homens e mulheres, heterossexuais e homossexuais, povos colonizados e colonizadores para justificar as diferenças.

O objetivo ideológico desse projeto de distinção era o de: ao estabelecer uma diferença formal racional entre os sexos e criar uma diferença de gênero, fazer emergir o machismo; ao legitimar uma diferença justificável entre as raças/etnias, constituir o mecanismo de racismo; ao legitimar uma diferença inteligível, nos planos de gênero e sexualidade, estabelecer os sexismos e as várias formas de lesbo/trans/homofobia.

No fundo o projeto ideológico, de cariz positivista e evolucionista, era o de negar direitos aos grupos e pessoas que passaram a ser vistos, dentro do discurso vigente como sendo diferentes. Portanto, mulheres, povos colonizados, homossexuais, negros e negras, por exemplo, passam a serem construídos de modo diferente para também serem tratados de modo distinto e, dessa forma, não terem acesso aos mesmos direitos da hegemonia cultural/econômica, sexual, étnica/racial e de gênero que constituía a burguesia dominante.

Contudo, de encontro com as teorias seculares do determinismo biológico - em torno da categoria de gênero, onde as fundamentações estabelecidas dos papéis sociais de homens e mulheres foram por muito tempo baseadas em explicações causais universais -, Scott (1991) em um viés mais filosófico, fala sobre gênero enquanto categoria social, que através de sua análise com enfoque construtivista nos possibilita compreender as dinâmicas sociais em torno das identidades subjetivas de homens e mulheres, bem como os papéis sexuais atribuídos a cada um, e os sistemas de relações sociais ou sexuais permeados por tal categoria. Nesse sentido, a autora salienta que:

\begin{tabular}{|c|}
\hline $\begin{array}{l}\text { termo 'gênero' faz par } \\
\text { uma tentati } \\
\text { mpreendida pel } \\
\text { ministas } \\
\text { ntemporâneas pa } \\
\text { ivindicar certo terrer } \\
\text { definição, pa } \\
\text { blinhar a incapacidac } \\
\text { steorias existente pa } \\
\text { pplicar as persistent } \\
\text { esigualdades entre } \\
\text { ulheres e os homens. } \\
\text { eu ver é significado qu } \\
\text { uso da palavra gêne } \\
\text { nha emergido nu } \\
\text { omento de grano } \\
\text { ervescência que e }\end{array}$ \\
\hline
\end{tabular}

O debate, então, em torno da compreensão do gênero enquanto categoria útil de análise estrutura a percepção e a organização de toda sociedade, influenciando as concepções, as construções, a legitimação e a distribuição do poder em si, ou seja, "o gênero é um campo primário no interior do qual, ou por meio do qual, o poder é articulado" (SCOTT, 1991, p. 19).

Em complementação, Butler (2017) assume uma posição não de construtivismo e sim de desconstrução, ou seja, considera que ao gênero são atribuídos significados culturais assumidos pelo corpo sexuado, pois, "supondo por um momento a estabilidade do sexo binário, não decorre daí que a construção de 'homens' aplique-se exclusivamente a corpos masculinos ou que o termo 'mulheres' interprete somente corpos femininos" (BUTLER, 2017, p. 26).

Para Butler (2017) a formulação usual de gênero no qual estão apensados os atributos culturais que os constroem e em seu oposto o sexo, é uma marca preestabelecida sobre o qual o gênero opera. Estas afirmações foram/são questionamentos das feministas do século XX. O que está em mote para a autora, é ir para além dos gêneros, pois o mesmo não deve ser visto e buscado enquanto origem e ou uma verdade sexual, (gênero feminino ou masculino) mas sim, enquanto investidas políticas denominadas como origem e causas de naturalizar categorias de 
identidades masculinas e femininas, ou seja, como homens e mulheres devem se comportar socialmente.

Sendo assim, Butler (2017) traz a proposta conceitual de performatividade de gênero, que "se baseia na reiteração de normas que são anteriores ao agente e que, sendo permanentemente reiteradas, materializam aquilo que nomeiam" (MISKOLCl; PELÚCIO, 2007, p. 259). Tratando da não fixidez de construções identitárias, Butler (2017) compreende que o gênero está para além do construtivismo cultural, uma vez que para a autora usar preceitos epistêmicos do construto social torna o gênero algo tão determinado e fixo para a identidade, quanto o sexo é para a biologia, na visão dos essencialistas. Nesse aspecto, diz Butler (2017)

A relação binária entre
cultura e natureza
promove uma relação de
hierarquia em que a
cultura impõem'
significado livremente à
natureza, transformando-
a, consequentemente,
num Outro a ser
apropriado para seu uso
ilimitado, salvaguardando
a idealidade do
significante e a estrutura
de significação conforme
modelo de dominação
(BUTLER, 2017, p. 33).

Destarte, vale destacar que ainda há muito que se discorrer sobre desconstrução de gênero e o entendimento de performatividade, não tendo a pretensão, nesse momento, de fazer tal debate em razão da limitação característica do ensaio, dessa forma, propusemos um breve percurso em relação ao gênero a fim de compreendermos como esta categoria implicou mudanças nos variados modos e discursos a partir dos quais se veem os corpos, o gênero e as sexualidades.

\section{SEXUALIDADE COMO CONSTRUÇÃO HISTÓRICA E SOCIAL}

É importante compreendermos que as práticas discursivas e não discursivas em torno do corpo e do prazer, segundo Michael Foucault (2009) permearam debates sobre a sexualidade. O sistema centrado na aliança, isto é, no casamento monogâmico e sobre a discussão realizada em torno do sexo atraiu duas modificações: uma sobre a "monogamia heterossexual", onde o campo das práticas e dos prazeres era assinalado pela regulação, controle da "perversidade sexual", preservação da relação matrimonial, o dever dos cônjuges e, a outra, se voltava à sexualidade das crianças, dos loucos, dos criminosos, dos que mantinham relação com pessoas do mesmo sexo. Assim, todas as formas de expressão da sexualidade (como exemplo, as homossexualidades) que não estivessem a serviço da procriação eram consideradas proibidas, infrações ou desvios.

Nessa perspectiva, Foucault (2009) assinala que as intervenções lançadas no campo da sexualidade e a rigidez em torno do comportamento moralmente congruente, foi balizada a partir de quatro regras: o saber e poder a respeito do sexo, quais sejam a histerização do corpo da mulher; a pedagogização do sexo da criança; a socialização das condutas de procriação; e a psiquiatrização do prazer. Estes grandes dispositivos discursivos formularam e legitimaram a sexualidade ditas normais (reprodutivas) e a normatização das sanções das sexualidades ditas anormais (não reprodutivas). Contudo, com os avanços das estruturas políticas e econômicas da sociedade, a partir do século XVIII, o dispositivo da aliança perde sua força ideológica e o dispositivo da sexualidade ganha espaço nas relações de saber e poder, para Foucault (2009):

[...] a sexualidade está
ligada a dispositivos
recentes de poder, esteve
em expansão crescente a
partir do século XVII; a
articulação que a tem
sustentado, desde então,
não se ordena em função
da reprodução; esta
articulada, desde a
origem, vinculou-se a uma
intensificação do corpo, à
sua valorização como
objeto de saber e como
elemento nas relações de
poder (FOUCAULT, 2009,
p. 101).

Nesse sentido, o autor concebeu a sexualidade como uma construção social inventada, basicamente, para submeter o corpo individual ao controle coletivo da sociedade onde conceito de sexualidade não é uma categoria natural, mas uma construção social que, como 
tal, só pode haver no contexto social. Assim, o autor afirma que:

[...] o dispositivo de aliança está ordenado para uma homeostase do corpo social, a qual é sua função manter, daí seu vínculo privilegiado com o direito; daí, também, o fato de o momento decisivo, para ele, se a 'reprodução'. O dispositivo da sexualidade tem, como razão de ser, não o reproduzir, mas 0 proliferar, inovar, anexar, inventar, penetrar nos corpos de maneira cada vez mais global (FOUCAULT, 2009, p. 118).

Desse modo, a sexualidade, assim como o gênero, é compreendida como construto social, cultural e histórico. Comungando da concepção de Foucault (2009), Weeks (2010) considera que a sexualidade é uma série de crenças, comportamentos, relações e identidades construídas no social e modeladas pelo processo histórico. Nesse sentido, determinada sexualidade pode ser vista como comportamento legítimo num dado momento particular. De acordo com Jeffrey Weeks, [...] os significados que damos à sexualidade e ao corpo são socialmente organizados, sendo sustentados por uma variedade de linguagens que buscam nos dizer o que o sexo é, o que ele deve e pode ser (WEEKS, 2010, p. 40).

Nessa perspectiva, Louro (2010) corrobora ao afirmar que a sexualidade é influenciada por processos culturais (incluindo os educacionais) e plurais, em que os corpos recebem significado social, e assim as performances dos gêneros masculino e feminino são entendidas a partir do contexto de uma dada cultura. As identidades sociais, de gênero e sexualidade, então, assim como as performidades de gênero são definidas e redefinidas em contextos culturais e históricos. Logo, Guacira Louro (2010) afirma que quando há uma transgressão das identidades de gênero ou sexual, modificando por seguinte a performance de gênero, o sujeito tem sua essencial alterada, e essa modificação é dificilmente compreendida pelas sociedades ocidentais que entendem as identidades de forma constante e fixa.

\section{AFIRMAÇÃO E (RE) CONHECIMENTO DA IDENTIDADE DA MULHER HOMOSSEXUAL}

As teorias e concepções hegemônicas reproduzidas no campo educacional, segundo Gadotti (2009), são ineficientes para a resolução de problemas que por sua vez, reforçam o aparelho ideológico do Estado. Assim, dentro de um sistema educacional capitalista, a educação acaba perdendo sua função transformadora e democratizadora da sociedade, reforçando e colaborando para as desigualdades. Apple (2003) pontua que a maioria de nossos modelos atuais de educação tende a ratificar ou, pelo menos, a não eliminar ativamente muitas das desigualdades que caracterizam a sociedade.

A guisa de compreensão, o processo educacional utiliza de sua estrutura de poder para docilizar, moldar e disciplinar corpos, que segundo Foucault $(2009 ; 2014)$ é uma técnica utilizada para exercício do poder, juntamente com a vigilância, para submeter os indivíduos incongruentes com a regra uma punição. Nessa perspectiva, (CORRIGAN, 1991, p. 200) reforça que é exercida na educação, uma pedagogia sutil e discreta que imputa, nos corpos, a produção e reprodução de uma masculinidade e feminilidade baseada em uma ideia concebida de naturalização, feitas no corpo e sobre o corpo.

A figura da mulher foi construída de forma subalterna e silenciada ao longo da história. Louro (1997, p. 106) afirma que a relação de gênero presente na construção histórica da representação da mulher era de extrema vigilância, inclusive no que tange suas vivências com a sexualidade "ela deveria afastar de sua figura as "marcas" distintivas da sexualidade feminina, seus trajes e seus modos deveriam ser, na medida do possível, assexuados. Sua vida pessoal além de irretocável deveria ser discreta".

Nesse sentido, se constrói uma normatização do lugar social que as mulheres deveriam/devem ocupar restrito à maternidade $\mathrm{e}$ aos cuidados maternos ditos "naturais". Em relação a isso, Laqueur (2001) diz que tanto na teoria do modelo do sexo único, onde o corpo da mulher era visto como uma versão imperfeita do corpo masculino, quanto na teoria da incomensurabilidade, onde a diferença do sexo torna-se a diferença de gênero. Diante disso, o papel social da mulher deixa de ser fundamentado na sua imperfeição em relação à falta do "calor" que a transformaria em ser "perfeito", homem, e passa a ser explicado a 
partir de sua diferença corporal. Isto posto, a mulher homossexual frente à visão essencialista da sexualidade, segundo Oliveira (2006) torna-se um perigo para o domínio masculino, assim como para a manutenção do papel social construído em torno da reprodução.

Louro (2010) assinala que ao transgredir a performance de gênero e identidade sexual as expectativas culturais e históricas registradas sobre o que é codificado na sexualidade e no gênero, lança no sujeito uma determinada alteração na sua essência, que na visão essencialista deveria ser fixa e constante, dessa forma a mulher homossexual é vista como um ser desviante da norma heterossexual estabelecida em nossa sociedade historicamente.

Frente a isso, Toledo (2010) expõe que: As lesbianidades ${ }^{1}$ são permeadas por um misto de exclusão que tem por base $o$ machismo, a misoginia, a heterormatividade e em torno desse jogo de poder, as mulheres lésbicas carregam dois problematizantes

marcadores sociais [...] um deles é 0 gênero (ser mulher) e, o outro, é a orientação sexual (relação afetivo-sexual com outra mulher). (TOLEDO, 2010, p. 6).

A autora afirma que existem vulnerabilidades e violências específicas vivenciadas por essas mulheres, motivadas por questões culturais de relação de poder que sob esses dois eixos problemáticos se manifestam no machismo e na lesbofobia, bem como das diferenças. Para Butler (2017), a "lésbica" emerge como um terceiro sexo, prometendo transcender à restrição binária ao sexo, imposta pelo sistema da heterossexualidade compulsória.

Deste modo, a regulação presente nos corpos, reflete também a regulação presente em certas identidades sexuais que cria uma atmosfera de segredo e surpresa frente à

\footnotetext{
1 Segundo Toledo (2008, p. 2) o termo "lesbianidades" é utilizado para nomear processos de subjetivação relativos a orientação sexual e identidade política, sexual e de gênero de mulheres como relações/práticas homoeróticas que se auto-atribuem o nome lésbica ou similar (entendida, sapa, sapatão, fancha, etc) que se sentem subjetivamente nesse "lugar" de diferença. É empregado no plural para referenciar todas as possibilidades de vivências das relações afetivos-sexuais de uma mulher com outra.
}

revelação (mesmo voluntária) de uma homossexualidade. E isso, faz com que muitas mulheres homossexuais permaneçam no "armário", a fim de não passar por constrangimentos, opressões, segregações e outras consequências que possam emergir no seu meio social frente a uma exposição (SEDGWIK, 2007).

É importante destacar que o dispositivo do "armário", segundo Sedgwick (2007), é empregado na sociedade para regular a vida de pessoas homossexuais e manter as vantagens da visibilidade e supremacia dos valores da cultura heterossexual. O controle e a regulação do segredo e da revelação em torno das questões relativas à homossexualidade, de acordo com a autora, são fundamentais para as estruturas econômicas, sexuais e de gênero da heteronormatividade.

O dispositivo do "armário", então, é uma estrutura definidora de opressão para por a sexualidade do individuo em um espaço intransponível sempre quando ela fosse reivindicada ou colocada à mostra. A este respeito Borillo (2010) afirma que

[...] o coming out ${ }^{2}$ pode também representar uma espécie de justificação social e de inscrição em uma identidade sexual. Nenhum heterossexual sonha em fazer seu coming out, uma vez que ele já se encontra no universo público; em razão de sua 'normalidade, ele usufrui desde sempre de presunção de heterossexualidade. Por sua vez, o homossexual, em decorrência de sua diferença, deve apresentarse, solicitar autorização e prevenir os 'normais' de sua entrada em um território que não é naturalmente destinado a ele. (BORILLO, 2010, p 103).

Nesse sentindo, observar-se que o dispositivo do "armário" é um processo que envolve uma série de negociações de ordem simbólica prática passando por quatro estágios específicos no processo de formação das

\footnotetext{
${ }^{2}$ Coming out refere-se à expressão sair do armário, ou seja, manifestar e assumir sua sexualidade publicamente.
} 
identidades: o primeiro é a "sensibilização", onde o indivíduo toma consciência de sua diferença; o segundo é a "significação", quando ele atribui um sentindo de desenvolvimento a essas diferenças; o seguinte e a "subculturização", estágio em que o indivíduo a partir do envolvimento com outras pessoas encontra seu reconhecimento subjetivo; e por último temos a "estabilização", o estágio da aceitação dos próprios sentimentos e modo de vida (WEEKS, 2000).

Dessa forma, acredita-se ser possível conjecturar que o dispositivo do "armário", enquanto fator desencadeador de constrangimentos e opressões "constrói" em contextos diferenciados, como se analisa nos estudos de Facchini e Barbosa (2006), situações que estabelecem as múltiplas formas do preconceito contra mulheres que vivenciam a lesbianidade enquanto prática sexual e ou estilo de vida.

No entanto, Toledo (2010) nos diz que estar no "armário" nem sempre é uma escolha, assim como sair dele. A autora, nos fala que em uma sociedade machista e lesbofóbica, a lesbianidade é silenciada e controlada como estratégia de invisibilizar tal prática, já que é inconcebível nas culturas sexistas reconhecer uma relação sem a presença do homem. Nesse sentido, mostra que a manutenção de uma ordem do exercício da sexualidade e a inflexibilidade do entendimento das expressões de gênero são ferramentas do biopoder, onde a verdade construída em torno da sexualidade e do próprio conceito de gênero funciona para produção e manutenção de relações de dominação e jogos de poder, onde se cria categorias de inferiores e processos de estigmatização.

Nessa perspectiva, podemos pensar no armário como sendo um dispositivo de controle característico do biopoder que segundo Foucault (1999) é um mecanismo que consiste aos dispositivos disciplinares do corpo, a regulação e a extração da força produtiva mediante controle, bem como fazer a regulação das massas por meios de relações de dominação existentes, ou seja, uma organização de poder sobre a vida. 0 dispositivo de poder corresponde:

[...] a um conjunto decididamente heterogêneo que engloba discursos, instituições, organizações arquitetônicas, decisões regulamentares, leis, medidas administrativas, enunciados científicos, proposições filosóficas, morais, filantrópicas. É isto um dispositivo de poder: estratégias de força sustentando tipos de saber e sendo sustentadas por eles. (FOUCAULT, 1999, p. 244-246)

Assim, cria verdades imutáveis e ou naturalizantes (que podem ser vistas em formas de códigos morais) de gênero que estabelecem modelos de discurso em torno dos estereótipos de lesbianidade onde esta sexualidade, no ideário do senso comum é exercida por mulheres masculinizadas, feias, mal amadas, desprezadas pelo sexo oposto ou que se frustraram com os homens (NAVARRO, 2002).

Nesse sentido, são criadas relações de poder apresentadas em formas de práticas discursivas estigmatizadas e estereotipadas. Foucault (1999, p. 88) afirma que o poder é fruto de relações com saberes que se auto afirmam enquanto verdades absolutas. Logo, práticas e instituições acabam legitimando essas verdades através do mecanismo de uso do mesmo. Segundo Numan (2004), são estabelecidas imagens negativas da sociedade, em que tais pessoas são vistas como inferiores e possuidores de caráter moral defeituoso e tais visões patológicas, acabam sendo internalizadas e de alguma forma tendem, portanto a incorporar e ou aceitar à sua autoimagem a conceitos negativos e depreciativos.

Assim, promover resignificações objetivas, concretas e subjetivas em indivíduos historicamente hostilizados - como mulheres que percorrem suas práticas, desejos e comportamentos pelas homossexualidades é uma forma de ascender, em seu (eu) sentidos positivos de sua autoimagem, onde a elas um olhar valorativo de si e do outro. Compreendemos que os processos de educação pautados em uma prática não hegemônica, que descontrói os sentidos opressores de gênero e de sexualidade através da inclusão do sujeito mulher e por consequente da homossexualidade feminina é importante, sendo necessário considerar que, para que isso ocorra, os estereótipos de gênero nos sentidos da mulher e do ideário de feminilidade sejam desnaturalizados, bem como as concepções hierarquizantes e impositivas dentro do campo 
do sistema de dominação que refletem no espaço escolar.

\section{CONSIDERAÇÕES FINAIS}

Este ensaio propôs apresentar uma discussão a respeito dos sentidos historicamente construídos acerca do gênero e da sexualidade percebidos como elaborações socialmente posicionadas a partir de um modelo de controle centrado na masculinidade normativa/reprodutiva. Apontamos concepções que envolvem a sexualidade como uma entidade permeada de valores que estigmatizam as diferenças sexuais não normativas. Nesse sentido, destacamos o dispositivo do "armário" como uma forma regulatória da vida social, especialmente das pessoas homossexuais, que em função de uma sociedade machista, patriarcal e lesbo/trans/homofóbica, acabam por tornar parte de suas vivências um segredo fundamentais para a manutenção das estruturas econômicas, sexuais e de gênero da heteronormatividade.

$\mathrm{Na}$ contramão do dispositivo do "armário", depreendermos o papel da educação para a contribuição e para afirmação e/ou reconhecimento das homossexualidades, em especial da mulher homossexual, visto que os processos educacionais se tornam, na contemporaneidade, uma das dimensões sociais por onde mais transitam sujeitos (as).

Dessa forma, pensamos na importância da educação como uma forma de luta contra a figura hegemônica centrada nos mecanismos de opressão que legitimam determinados sujeitos ao passo que excluem uma parcela significativa da sociedade à margem dos padrões reguladores heteronormativos - que exercem poder sobre nossos corpos e buscam uniformizar a identidade do gênero por via heterossexualidade compulsória. Ratificamos, em sintonia com o pensamento de Louro (2010) que a educação tem uma tarefa bastante difícil, qual seja: a de contribuir para que se dizimem preconceitos, desconstrua o ideário de um modelo de sexo e de uma única performatização de gênero aos moldes da matriz heterossexual, subvertendo o discurso de maternidade e da heterossexualidade compulsória.

\section{REFERÊNCIAS}

APPLE, M. Educando à Direita. Porto Alegre: Artmed, 2006.
BORILLO. D. Homofobia: história crítica de um preconceito. Trad. Guilherme João de Freitas Teixeira. Belo Horizonte: Autêntica Editora, 2010.

BUTLER, J. Problemas de gênero: feminismo e subversão da identidade. 13ㅇe ed. Rio de Janeiro: Civilização Brasileira, 2017.

CORRIGAN, P. Making the boy: meditations on what Grammar school did with, to and for my body. In LOURO, Guacira (org.). O Corpo Educado: Pedagogia da sexualidade. Tradução: Tomaz Tadeu da Silva, 2. Ed. Belo Horizonte: Autêntica, 2000.

FOUCAULT, M. Vigiar e Punir: Nascimento das prisões. Petrópolis, RJ: Vozes, 2014.

FOUCAULT, M. História da sexualidade 1: A vontade de saber. Rio de Janeiro: Graal ed., 2009.

FOUCAULT, M. Sexualidade e Poder. In: Ditos e Escritos V: Ética, sexualidade e política. Rio de Janeiro: Forense Universitária, 2006. p. 56-76.

GADOTTI. M. Pensamento Pedagógico Brasileiro. 8. Ed. São Paulo: Ática. 2009.

LAQUEUR, T. W. Inventando o sexo: corpo e gênero dos gregos a Freud. Rio de Janeiro: Relume Dumará, 2001.

LOURO, G. Currículo, gênero e sexualidade. Editora Porto, 2000.

LOURO, G. Gênero e Sexualidade: pedagogias contemporâneas. Pro-posições, v.19, n.2, p.56, maio/ago. 2010.

MISKOLCI, R. PELÚCIO, L. Fora do sujeito e fora do lugar: reflexões sobre performatividade a partir de uma etnografia entre travestis. Revista Gênero, Niterói v.7, n .2, p. 255-267, 1. Sem. 2007.

NAVARRO, S. T. Feminismo e Lesbianismo: quais os desafio?. Labrys, estudos feministas. n.1-2, julho/dez. 2002

NUNAN, A. Violência doméstica entre casais homossexuais: o segundo armário?. PSICO, v.35, n.1, p. 69-78., 2004. 
NUNAM, A. Homossexualidade e Discriminação: o preconceito sexual internalizado. 2007. Tese (Doutorado em Psicologia) - Programa de pósgraduação em psicologia do departamento de psicologia da PUC-RIO - PUC Rio de Janeiro, 2007.

OLIVEIRA, M. V. Um olhar interseccional sobre feminismos, negritudes e Lesbianidades em Goiás. 2006. Dissertação (Mestrado em Sociologia) - Faculdade de Ciências Humanas e Filosofia, Programa de Pós Graduação em Sociologia - Universidade Federal de Goiás, Goiás, 2006.

REYNOLDS, R. Postmodernizing the Closet. Sexualities, v. 2, n. 3, p.346-349, 1999.

SCOTT, J. Gênero: Uma categoria útil para análise histórica. Recife: SOS corpo, 1991.

SEDGWICK. E. K. A epistemologia do armário. Cad. Pagu, Campinas, n. 28, p. 19-54, 2007.

TOLEDO, G. L. Biopoder, gêneros e sexualidades: Articulando desejo, (in) visibilidade e processo de exclusão na vivência das lesbianidades. Fazendo gênero 9: Diásporas, Diversidade, Deslocamentos; Florianópolis, 23 a 26 de agosto de 2010.

TOLEDO, G. L. Lesbianidade e Biopoder: um olhar genealógico. Revista de psicologia da UNESP, v.7, p. 176, 2008.

WEEKS, J. O corpo e a sexualidade. In: 0 corpo educado: Pedagogias da Sexualidade. 2. ed. Autêntica, Belo Horizonte, 2000.

Submetido em: 05/09/2018

Correções Obrigatórias: 29/11/2018

Aceite Final em: 13/12/2018 